\title{
RESULTADOS CIENTÍFICOS DO CRUZEIRO DO "BAEPENDI" E DO "VEGA" À ILHA DA TRINDADE
}

\author{
Contribuição para o conhecimento da plataforma insular \\ da Ilha da Trindade
}

\author{
W. Besnard
}

A expedição organizada pelo sr. Ministro João Alberto Lins de Barros à Ilha da Trindade, iniciou-se em fins de maio de 1950, empregando nos seus trabalhos dois destróiers da Marinha Brasileira, aos quais, mais tarde, se uniu um barco de pesca italiano denominado "VEGA".

Os principais objetivos da expedição foram: estudar os recursos naturais da Ilha para saber se lá poderia ser mantida uma comunidade agrícola e efetuar pesquisas científicas complementares sôbre êsse acidente geográfico ainda muito pouco conhecido.

A Ilha da Trindade localiza-se a cêrca de 640 milhas $(1.185 \mathrm{~km})$ da costa brasileira, ao longo do paralelo de Vitória, no Estado do Espírito Santo. Suas coordenadas são as seguintes: $20^{\circ} 30^{\prime} 36^{\prime \prime}$ de lat. S. e $29^{\circ} 19^{\prime} 26^{\prime \prime}$ de long. W., medidas do Pico Desejado, o mais alto da Ilha e situado mais ou menos no seu centro $(600 \mathrm{~m})$. O aspecto geral da Iilha não é, como no caso de sua vizinha, a de Martim Vaz, o de um rochedo surgido do mar, mas antes o de um fragmento de paisagem lunar lançado sôbre o mar, todo eriçado de picos e de cristas desordenadas. A sua superfície é pequena, não ultrapassando de $7 \mathrm{~km}^{2}$. Nessa área existem, entre infinitas outras saliências de secundária importância, representadas por cristas e cumiadas, 22 picos cuja altura vai de 300 a $600 \mathrm{~m}$.

A forma irregular da Ilha pode ser comparada, de certo modo, à de uma elipse cujo maior eixo é de mais ou menos $5 \mathrm{~km}$. e o menor de $1.800 \mathrm{~m}$.; sua origem é vulcânica, sendo ela formada por um conjunto de rochas eruptivas e tufos vuleânicos.

A posição da Trindade, pelo fato de se achar a mesma muito afastada do continente, é extremamente interessante; 640 milhas, isto é, 3 dias de viagem de um eargueiro, já representam uma distância considerável. Mais notável ainda é o fato de ser ela cireundada por todos os lados por uma depressão enorme, como se pode verificar pela carta geográfica n. 20 : Brasil - Costa Leste - de Recife ao Rio de Janeiro, publicada em $30 \mathrm{de}$ junho de 1948, 1. ${ }^{a}$ edição, pela Diretoria de Hidrografia e Navegação, do Ministério da Marinha, com pequenas correções feitas em 1949. O 
grupo Trindade-Martim Vaz, apesar de estar relacionado com o continente através de uma série de bancos acha-se circundado, num raio de $240 \mathrm{mi}$ lhas, por profundidades superiores a $4.000 \mathrm{~m}$., que podem, portanto, ser consideradas profundidades abissais. Baseando-nos nos dados da mencionada carta, pode-se constatar que as sondagens, infelizmente muito raras nesse trecho do oceano, revelam já mais ou menos a 40 milhas da Trindade, fundos de $4.861 \mathrm{~m}$., a 50 milhas da Ilha, dois pontos com 4.927 e $4.956 \mathrm{~m}$., enfim, a 30 milhas de Martim Vaz, fundos de $4.795 \mathrm{~m}$.

Quanto à earta detalhada da Ilha (n. 21 - Brasil - Ilhas ao Largo. Ilha da Trindade. Publicada em novembro de 1938, pela referida D. H. N. e com pequenas correções em 1946 e 1948), apresenta sondagens que não ultrapassam de $82 \mathrm{~m}$. de profundidade, afora uma série de 7 sondagens esealonadas entre 100 e $346 \mathrm{~m}$. (mapa)

Ao se iniciar a Expedição, não tínhamos outras indicações além destas, o que representava uma documentação insuficiente, não só para se poder ter uma idéia, mesmo aproximada da extensão e características da plataforma insular, mas também para se poder estabelecer um programa definido sôbre os trabalhos a serem executados. Tanto assim, que a única hipótese que aventamos ao iniciar a viagem, isto é, a da existência de uma plataforma insular comum à Trindade e Martim Vaz, ao que parece, revelou-se errônea. Se bem que ainda não se possa afirmar êsse fato, parece muito provável que as duas ilhas se encontrem separadas por fundos de muitos milhares de metros.

Quanto à carta detalhada da Ilha (n. 21), deve-se assinalar uma circunstância assaz importante. Nela, acham-se assinaladas muitas sondagens em número de 290. Evidentemente foram realizadas com a finalidade de determinar as áreas de ancoragem e desembarque, o que é muito compreensível. Assim sendo, foram estudadas as mais próximas à Ilha, o que faz com que, das 290 sondagens eitadas, mais de 200 tenham sido efetuadas sôbre fundos de menos de 30 metros, e as demais entre 30 e 82 m., afora a série acima mencionada, entre 100 e 346 m. Em virtude de não dispormos de bareo hidrográfico, e visto como o nosso objetivo principal era determinar a extensão da plataforma insular, sòmente nos preocupamos com os fundos de mais de $30 \mathrm{~m}$. Tendo sido êstes determinados, tínhamos sòmente 90 pontos já estabelecidos, em tôda a área a ser estudada, e verificamos que os resultados obtidos com o ecobatímetro não correspondiam às profundidades assinaladas na carta. Esta questão será discutida mais tarde, ao tratarmos da execução do trabalho; limitar-nos-emos aqui a assinalar o fato. É evidente que não podemos garantir exatidão matemática nas nossas sondagens, mas repetidamente controlamos os resultados obtidos por meio do ecobatímetro com os conseguidos por via mecânica com a sonda Thomson; além disso, a localização dos pontos de sondagem, na carta não apresenta a menor dúvida, visto como foram determinados, com todo o cuidado pelos oficiais do "Baependi", através de aparelhos modernos e de grande precisão.

Evidentemente não podemos apresentar hipótese alguma tendente a explicar tais divergências; por outro lado, vemo-nos forçados a considerar 
como válido o levantamento que executamos e a tomá-lo como base do presente estudo.

Conforme se depreende do trabalho de Machado (1951, p. 9.6 ) constatamos algumas pequenas divergências entre as profundidades indicadas pela sonda Thompson e as séries batimétricas traçadas sôbre a carta da expedição. Tais diseordâncias são pouco numerosas e, por assim dizer, inevitáveis. De fato, tôda linha batimétrica não passa de uma hipótese em todos os seus pontos, menos naquêles determinados por sondagens. Ora, nesse caso, as estações foram trabalhadas posteriormente à determinação dos fundos, sem tomar em consideração as linhas de sondagem, visto como a posição das estações tinha sido determinada de antemão. De qualquer modo, apesar dessas pequenas discordâncias, as sondagens nelas realizadas confirmaram plenamente a exatidão do levantamento dos fundos.

As condições em que se trabalhou, foram as seguintes: do ponto de vista do levantamento da plataforma insular, o "Baependi" encarregado da execução de todos os trabalhos oceanográficos, apresentava condições ótimas. Antes de mais nada, desejamos apresentar os nossos agradecimentos do seu comandante e à oficialidade do vaso de guerra, todos, indistintamente, empenhados no trabalho com a máxima competência e entusiasmo. A aparelhagem de bordo era boa e abundante, permitindo uma rigorosa determinação nas sondagens. $O$ único detalhe que ñão correspondeu totalmente foi o tipo de ecobatímetro, eujo aleance era insuficiente, pois não ultrapassava de $200 \mathrm{~m}$. Tendo em vista, porém, a pesquisa que tencionávamos fazer, êsse aparelho foi suficiente para determinar a plataforma insular, que, como veremos mais adiante, apresenta uma queda brusea entre 100 e 120 metros.

Por outro lado, as condições de trabalho a bordo eram insuficientes para a tarefa relativa a dragagens, pescas planetônicas, tomadas de amostras de superfície, ete. Várias são as causas: antes de tudo, as máquinas do navio, por serem demasiado possantes, impediam uma marcha bastante lenta para permitir levar a bom têrmo êsse tipo de investigação; procuramos remediar êsse inconveniente avançando por pequenos arrancos, providência que, entretanto, prejudicou consideràvelmente os resultados. Além disso, afora o guincho da âncora, não havia outros a bordo, o que complicou sobremaneira as operações, que tiveram de ser efetuadas através de ordens telefônicas.

\section{O LEVANTAMENTO DA PLATAFORMA INSULAR}

Como já dissemos, as profundidades indicadas na carta n. 21, que serviu de ponto de partida, não concordam com as sondagens que realizamos. Por êsse motivo e visto termos verificado, logo de início, que nas proximidades de $100 \mathrm{~m}$. tôda indicação de fundo recolhida pelo ecobatí- 
metro parava bruscamente, tivemos a impressão de que o aparelho estava com defeito. Suspendemos então, o trabalho, e passamos a aguardar a sua verificação por parte de um especialista que se achava a bordo. Os contrôles realizados com a sonda mecânica confirmaram a opinião do engenheiro que declarou estar o aparelho em perfeitas condições. Referimo-nos a esta particularidade para demonstrar que as discordâncias verificadas foram devidamente controladas.

Obtida a certeza do perfeito funcionamento do ecobatímetro, procedeu-se à determinação das profundidades da plataforma insular, que foi limitada a fundos maiores de $30 \mathrm{~m}$., já que a vizinhança imediata da orla da ilha seria perigosa para um navio do calado do "Baependi". Infelizmente, a ausência de embarcações do tipo das lanchas hidrográficas ("vedettes"), assim como a falta de tempo impediu-nos de examinar a faixa entre 0 e $30 \mathrm{~m}$.

Desde o comêço verificamos ser a plataforma insular muito estreita. Quanto à plataforma continental, não temos nenhuma indicação exata, mas baseando-nos em algumas sondagens efetuadas com a sonda Thomson e os dados recolhidos mais tarde pelos pescadores do "Vega", que se utilizavam do espinhel e de linhas, o talude parece apresentar uma queda assaz brusca, que explica o fato de se obter raramente uma indicação além da linha de $100 \mathrm{~m}$. de profundidade, sendo que estas não ultrapassavam a quota de $128 \mathrm{~m}$. As séries de sondagens foram realizadas segundo uma distribuição predeterminada, o que explica a diseordância entre o número de ordem das estações e sua sucessão cronológica; a sequência preestabelecida, porém, não pôde ser rigorosamente seguida em virtude dos ventos dominantes. $O$ método de marear a localização das sondas (profundidades), foi a seguinte: no ponto em que se achava o ecobatímetro, foram destacados dois observadores, um na mira do aparelho e o outro anotando a leitura. Um terceiro assinalava na carta os pontos transmitidos pelo telefone do alto do passadiço, onde estavam outros observadores determinando os pontos por intermédio do radar, do telêmetro e de uma bússola de observação, bem como pelo perserutar pontos e picos já conhecidos da ilha.

\section{CARACTERES DA PLATAFORMA INSULAR DA ILHA}

Como já foi dito, a plataforma insular é relativamente muito exígua e sua queda inicia-se mais ou menos a $100 \mathrm{~m}$. de profundidade. Sua largura é bastante irregular, variando entre $740 \mathrm{~m}$. e $2.950 \mathrm{~m}$. Para se ter uma noção mais exata de sua configuração escolhemos arbitràriamente 8 linhas de sondagem dentre as que nos pareceram mais earacterísticas e delineamos cortes geográficos. A direção e a posição dêsses cortes acham-se indicadas no mapa pelas linhas numeradas de 1 a 8 . Êsses gráficos foram desenhados eom duas escalas; $1 .^{\circ}$ - a parte horizontal e a elevação em relação à terra correspondem às da carta da ilha (n. 21$) ; 2 .^{\circ}$ - as verticais submarinas, isto é, as profundidades, foram 
multiplicadas por 4 para pôr em melhor relêvo a linha do fundo. A escala da carta n. 21 é a natural de 1:15.000. Como se pode depreender pelo exame da tabela abaixo, os cortes mostram qual a largura da plataforma, assim como a sua inclinação e profundidade máxima ao longo da respectiva linha.

\begin{tabular}{|c|c|c|c|c|c|c|c|}
\hline Corte & $\begin{array}{c}\text { Dist. da } \\
\text { beira ao } \\
\text { limite da } \\
\text { plat. }\end{array}$ & $\begin{array}{l}\text { Profundi- } \\
\text { dade } \\
\text { máxima }\end{array}$ & $\begin{array}{c}\text { Inclina- } \\
\text { ção } \\
\text { em \% }\end{array}$ & Corte & $\begin{array}{l}\text { Dist. da } \\
\text { beira ao } \\
\text { limite da } \\
\text { plat. }\end{array}$ & $\begin{array}{l}\text { Profundi- } \\
\text { dade } \\
\text { máxima }\end{array}$ & $\begin{array}{c}\text { Inclina- } \\
\text { ção } \\
\text { em \% }\end{array}$ \\
\hline I & $2.950 \mathrm{~m}$. & $128 \mathrm{~m}$. & $4,34 \%$ & V & $800 \mathrm{~m}$. & $109 \mathrm{~m}$. & $13,62 \%$ \\
\hline II & $1.900 \mathrm{~m}$. & $108 \mathrm{~m}$. & $5,68 \%$ & VI & $2.500 \mathrm{~m}$. & $116 \mathrm{~m}$. & $4,64 \%$ \\
\hline III & $740 \mathrm{~m}$. & $85,2 \mathrm{~m}$. & $11,51 \%$ & VII & $780 \mathrm{~m}$ & $100,6 \mathrm{~m}$. & $12,90 \%$ \\
\hline IV & $2.300 \mathrm{~m}$. & $106 \mathrm{~m}$. & $4,60 \%$ & VIII & $1.520 \mathrm{~m}$. & $116,5 \mathrm{~m}$. & $7,66 \%$ \\
\hline
\end{tabular}

A maior profundidade média verificada foi de $108,3 \mathrm{~m}$.

A inclinação média da plataforma insular é de $8,12 \%$. Como se pode verificar pelos esquemas dos cortes, constata-se um caráter comum a tôdas as séries, afora a de n. 6 , isto é, uma queda muito rápida entre $0 \mathrm{~m}$. de profundidade e as primeiras sondagens, isto é, entre 0 e mais ou menos 40 metros.

O corte n. 6, que sob êste ponto de vista, pode ser considerado anormal, inicia-se no sopé de um acidente geográfico muito curioso, denominado Paredão, representado por um rochedo tão abrupto, que parece ter sido cortado com uma faca. A sua parte distal, provàvelmente bastante extensa, terá desmoronado e tombado ao mar, entulhando destarte, um vasto espaço com blocos rochosos. Assim sendo, deixaremos de lado o corte n. 6 na avaliação da inclinação média do fundo, nas vizinhanças imediatas da ilha; de fato, êste corte mostra que, pelo espaço de cêrea de 500 metros junto à costa, o fundo está entulhado de rochedos derivados do desmoronamento.

Quanto aos 7 cortes considerados normais, sua inclinação varia entre $14,5 \%$ e $66 \%$, sendo a média cêrea de $30 \%$, no trecho compreendido entre $0 \mathrm{~m}$. e cêrea de $40 \mathrm{~m}$. de profundidade. Não se deve, entretanto, esquecer que êstes números são apenas aproximativos, visto como é difícil marear distâncias tão pequenas numa carta, mesmo se nela o contôrno da ilha fôsse rigorososamente exato. De qualquer modo, não há dúvida de que existe uma inclinação mais forte nas imediações da ilha.

Os fundos. - Os fundos da plataforma podem ser divididos em duas partes distintas, mais ou menos separadas uma da outra: a zona litorânea, de cêrea de $200 \mathrm{~m}$. e a zona pròpriamente pertinente à plataforma. 
Zona litorânea. - Esta zona é essencialmente rochosa. Dada a grande quantidade de escarpas abruptas e rochosas e o estado muito adiantado de erosão das rochas cristalinas que formam a ilha, é natural que as proximidades da beira se originem da desagregação das rochas cristalinas acima citadas, sendo que, por vêzes, êstes blocos de dimensões consideráveis, podem dar origem até a pequenas ilhotas ou penínsulas. Sòmente defronte das praias, como por exemplo a Praia dos Portuguêses, a das Tartarugas, é que tais desmoronamentos são menos acentuados, havendo, todavia, uma zona rochosa da qual falarei mais tarde. Nos lugares em que a costa é alta e a arrebentação forte, nos primeiros $20-30 \mathrm{~m}$. afastados da costa, existe um amontoado de rochas de origem sedimentária e sem qualquer cimentação entre elas. A partir da linha de 6-7 m. de fundo, há uma zona de sedimentação preenchendo o espaço entre as rochas que se tornam cada vez mais raras. A sedimentação compõe-se de uma mistura de aglomerados calcáreos de origem orgânica recente, e de certa quantidade de fragmentos das rochas vulcânicas da ilha; êstes dois componentes encontram-se aproximadamente na seguinte proporção: cêrea de $80 \%$ de aglomerados e $20 \%$ de fragmentos rochosos. Â medida que aumenta a distância da costa, diminue a quantidade dêstes, de modo que a eêrea de $100 \mathrm{~m}$., as dragas frequentemente só trazem à tona uma mistura de aglomerados com areia grossa, calcárea, derivada da desagregação dos aglomerados, e provàvelmente, dos baneos de Lithothamnion, outras formações semelhantes da zona da arrebentação, da qual falarei mais adiante. Nessa areia existem também fragmentos de conchas de moluscos e uma porcentagem bastante alta de fragmentos de rochas cristalinas, quase todos muito escuros ou negros.

A distribuição dos fundos é, naturalmente, muito desigual, dependendo dos caracteres da costa, frente à qual se eneontram. Em face dos paredões escarpados e especialmente diante dos cabos, a sequência que acabamos de expôr é alterada pela presença de verdadeiros rosários de rochas vulcânicas projetadas para o largo. Em outros pontos, a sequência dos fundos parece ser muito regular e homogênea em tôda a volta da ilha. Além da zona rochosa, os fundos são arenosos, a princípio constituidos por areia relativamente grossa, gradualmente mais fina em direção ao largo, vindo por fim areia fina e socada numa distância de cêrca de $400 \mathrm{~m}$. da beirada, zona em que a draga sòmente morde o fundo se for precedida de um lingote de uns $20 \mathrm{~kg}$. Nesses fundos de areia fina, existem bolas de aglomerados pousados sôbre o fundo, sendo frequentemente retirados com linhas. Resumindo, a plataforma insular tem eontôrno muito irregular. Sua largura varia de 700 a 3.000 metros, e sua inclinação oscila entre 17 e $36 \%$. Dêsse ponto em diante, a queda parece ser muito abrupta, mas não se obteve ainda dados precisos a êsse respeito. Todavia, pudemos verificar a exatidão da já mencionada carta n. 21, quanto à localização e a profundidade dos baixios, e quanto ao fato de ser a ilha cercada, a pequena distância, de grandes profundidades.

Os fundos da plataforma são relativamente muito homogêneos e apresentam 3 zonas distintas sem limites nítidos entre elas, a saber: $1 .^{\mathrm{a}}$ Zona: 
litorânea, formada por fundos rochosos; $2 .^{\mathrm{a}}$ Zona: compreende os três elementos: rochas, aglomerados e areias; $3 .^{\mathrm{a}}$ Zona: fundos arenosos.

Parece-nos necessário fornecer alguns dados sôbre os três constituintes que acabamos de mencionar.

Os fragmentos de rochas. - Todos êsses rochedos, provenientes da desagregação da ilha, são de origem vulcânica e constituidos sobretudo por fonolitos, tufos vulcânicos, granitos parcialmente alterados e uma certa quantidade de basalto. Muitas dessas rochas já se encontram revestidas por uma ganga de algas calcáreas, sobretudo Lithothamnion, assim como outros organismos com envoltórios calcáreos.

Os aglomerados. - Como já foi dito, usamos êste têrmo no sentido vulgar da palavra, para designar bolas formadas em grande parte por Lithothamnion; de um modo geral, essa alga parece constituir o núcleo dos aglomerados, cujo crescimento e desenvolvimento é devido à associação da alga com numerosos comensais animais e vegetais. Na zona litorânea existem numerosos tufos de Lithothamnion ainda vivos, sem estarem associados a outros organismos quaisquer; o tamanho médio dêsses tufos é de 4-5 cm. de diâmetro, havendo alguns muito maiores. A composição química dos aglomerados é relativamente constante e os carbonatos, seu principal constituinte, variam sòmente entre 89,2 e $94,0 \%$, como se pode verificar pela análise constante do quadro da pág. 44.

$O$ alto teor em matérias orgânicas explica-se pelo fato da grande maioria dos aglomerados ser muito rica em organismos diversos, tais como: algas vivas, calcáreas ou não, poliquetos, briozoários, lamelibrânquios, ete., sem contar os tecidos vivos do próprio Lithothamnion.

As areias. - Como já dissemos, existem dois tipos de areia: um relativamente grosso e outro fino. Não existe, naturalmente, limite brusco de transição, mas, da beira para o largo, os grânulos tornam-se gradualmente mais finos. Foi feita a análise de uma amostra de cada tipo, e o peneiramento deu o resultado constante à pág. 45 .

A análise química forneceu resultados inesperados, se bem que lógicos. Era de se esperar uma maior riqueza de earbonatos, dada a grande abundância de concreções calcáreas em tôda a zona litorânea, a enorme friabilidade destas, e a agitação permanente na faixa de arrebentação. O teor em carbonatos, revelados pela análise química é de $15,8 \%$, o que provàvelmente é devido a uma grande riqueza da água em $\mathrm{CO}_{2}$. A porcentagem de compostos insolúveis na água régia é bastante alta, elevando-se a 41,5\% do pêso sêco. Depois de ter sido feita a análise, ainda registramos uma certa abundância de grãos ferruginosos escuros, provenientes da desagregação das rochas. (Vide quadro da pág. 46). 


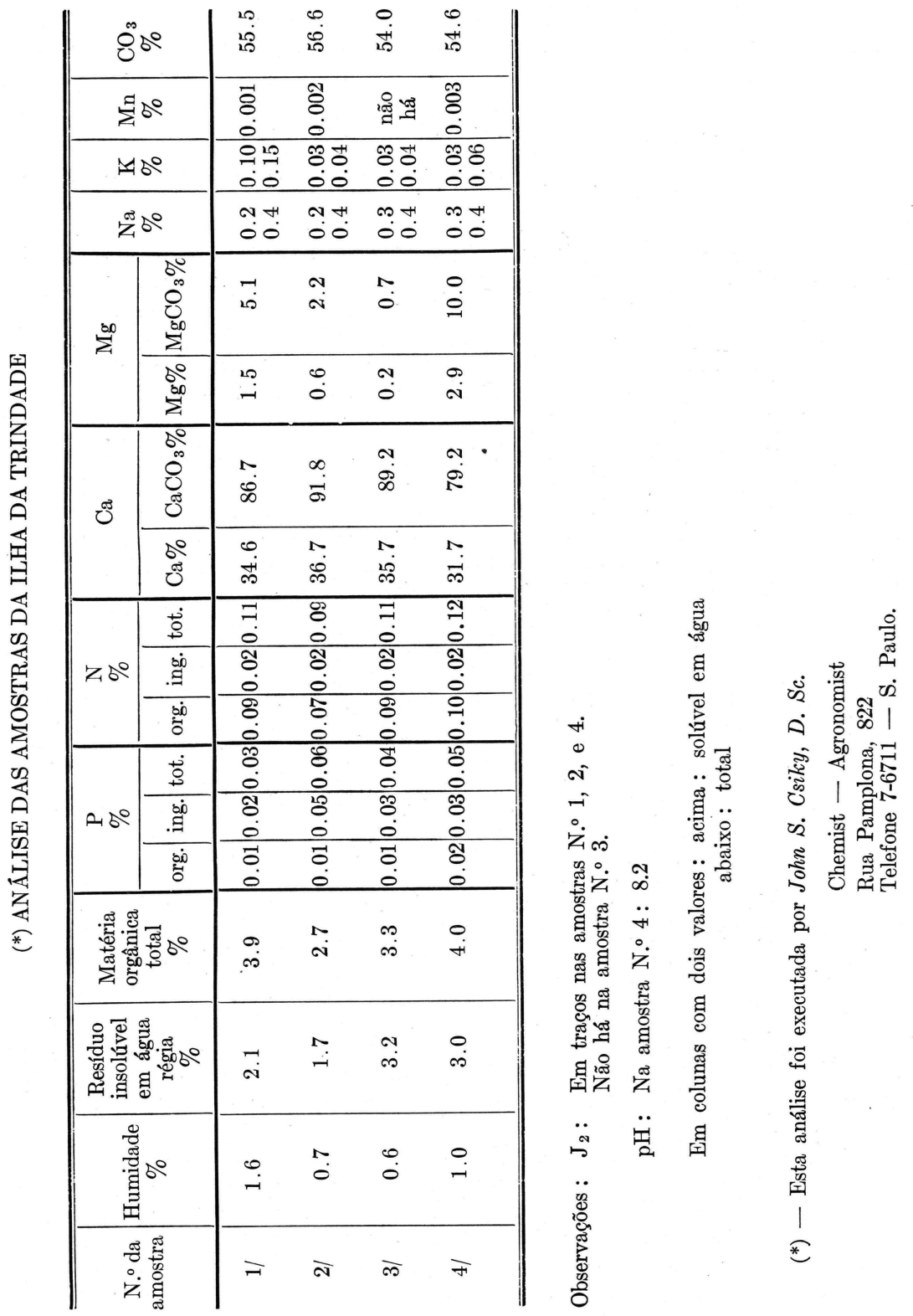




\begin{tabular}{|c|c|c|c|c|c|c|}
\hline 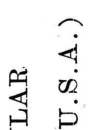 & $\begin{array}{l}\text { 弄 } \\
\vee\end{array}$ & \begin{tabular}{l|} 
Na \\
0 \\
0 \\
0 \\
$V$
\end{tabular} & $\mid \begin{array}{c}0 \\
0 \\
0 \\
0\end{array}$ & $\stackrel{29}{\circ}$ & $\stackrel{8}{0}$ & 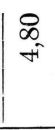 \\
\hline 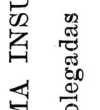 & 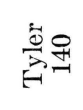 & $\begin{array}{l}\text { ㅍ } \\
\text { है } \\
0\end{array}$ & $\stackrel{10}{-\infty}$ & $\stackrel{\Re}{\stackrel{9}{*}}$ & $\begin{array}{l}\stackrel{20}{\circ} \\
\stackrel{1}{7}\end{array}$ & 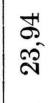 \\
\hline 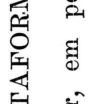 & $\stackrel{8}{8}$ & $\begin{array}{l}\stackrel{8}{+} \\
0 \\
0\end{array}$ & $\begin{array}{l}18 \\
8 \\
7\end{array}$ & $\begin{array}{l}8 \\
18 \\
0\end{array}$ & $\begin{array}{l}10 \\
10 \\
\infty \\
\infty\end{array}$ & $\begin{array}{l}\infty \\
\text { N } \\
\text { ही }\end{array}$ \\
\hline 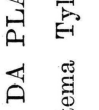 & $\infty$ & $\begin{array}{l}\text { 点 } \\
\text { - }\end{array}$ & $\frac{20}{\vec{A}}$ & $\overrightarrow{\vec{N}}$ & $\begin{array}{l}\infty \\
\stackrel{\infty}{N} \\
=\end{array}$ & $\begin{array}{l}8 \\
\text { ô } \\
\text { r. }\end{array}$ \\
\hline 䭆 & 오 & $\begin{array}{c}\hat{s} \\
\text { â. } \\
0 \\
0\end{array}$ & $\begin{array}{l}\hat{o} \\
\hat{N}\end{array}$ & 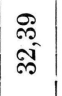 & $\stackrel{8}{\circ}$ & $\frac{R}{R}$ \\
\hline $\begin{array}{l}8 \\
\text { 18 }\end{array}$ & శి & $\begin{array}{l}2 \\
28 \\
0 \\
0\end{array}$ & 8 & $\vec{\sigma}$ & $\stackrel{8}{8}$ & $\stackrel{20}{\circ}$ \\
\hline 每 & ㅇำ & 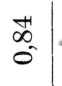 & 곤 & $\frac{\pi}{\infty}$ & $\stackrel{8}{0}$ & 80 \\
\hline & $\stackrel{\sim}{1}$ & $\begin{array}{l}8 \\
\text { i }\end{array}$ & $\begin{array}{l}0 \\
10 \\
0 \\
0\end{array}$ & $\begin{array}{l}\text { F } \\
\text { I }\end{array}$ & 0 & 0 \\
\hline 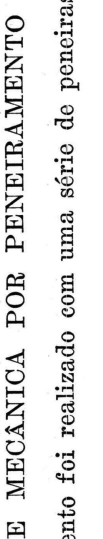 & 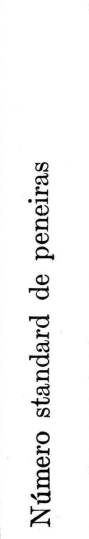 & 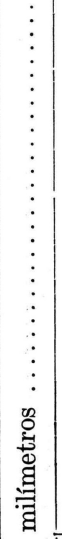 & 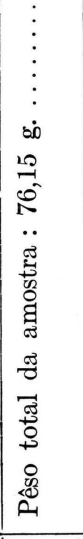 & 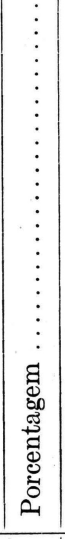 & 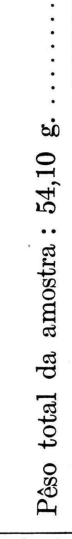 & 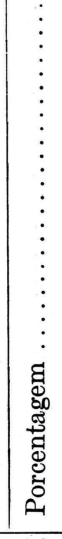 \\
\hline 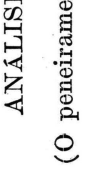 & & 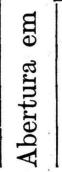 & 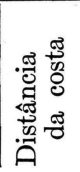 & 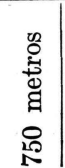 & 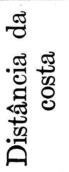 & 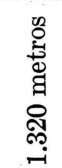 \\
\hline
\end{tabular}




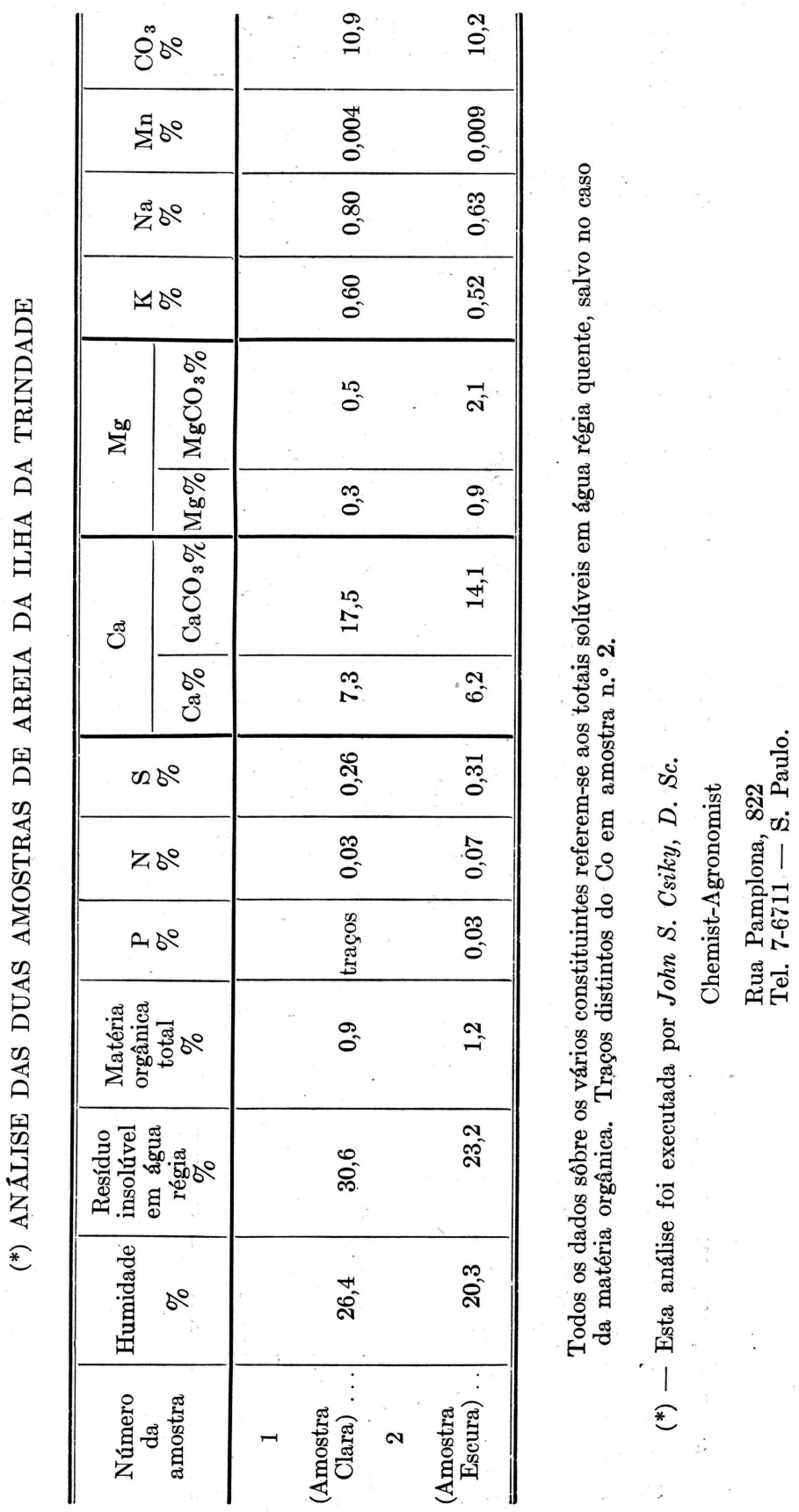


As praias. - Há dois tipos de praias na Ilha da Trindade: um de cascalho e outro de areia fina. A maior, na costa NE é a Praia dos Portuguêses, inteiramente constituida por eascalho grosso, enquanto que a Praia das Tartarugas, sua vizinha, é formada por areia fina. Nos dois casos, a cêrea de $10 \mathrm{~m}$. da beira, na maré baixa, existem fundos rochosos, em grande parte providos com pedras recobertas por algas calcáreas e respectivos comensais.

Nas praias de cascalho, existem frequentemente recifes de Lithothamnion formando terraços (récifs trottoirs) levemente inclinados, sendo que o superior se encontra mais ou menos descoberto, e o inferior cêrea de $30 \mathrm{~m}$. abaixo; nêles encontra-se muito seixo rolado. Do nível da maré alta para cima, a praia é tìpicamente formada por seixo rolado, sendo que o diâmetro do mesmo é de cêrea de $15 \mathrm{~cm}$. em média.

As praias de areia fina e, de um modo especial, a Praia das Tartarugas, frequentemente são muito extensas na direção do interior da ilha, se bem que sua inclinação seja considerável. Dêsse modo, a Praia das Tartarugas extende-se até o sopé do Pão de Açúcar que está na costa SW, aleançando assim cêrea de $400 \mathrm{~m}$. de extensão, subindo do fundo até cêrea de 5-6 m. acima do nível médio do mar. Existem ainda pequenas praias, tanto do primeiro, como do segundo tipo, entre os cabos e arestas rochosas que constituem a beira da ilha.

Resumindo, os fundos marinhos da plataforma insular, são relativamente homogêneos. Perto da margem existem fragmentos de rochas, passando-se progressivamente a zonas onde estas são cada vez mais escassas e o espaço entre elas preenchido por formações calcáreas de origem sedimentária e que designamos com o nome de aglomerados. Finalmente, mais ao largo, existem fundos arenosos, dotados de areia bem socada e tanto mais fina quanto mais distante da costa.

Os nove décimos da costa são constituidos por paredões rochosos e escarpados, inaccessíveis; o restante é representado por praias de cascalho grosso frequentemente orladas por terraços de recifes, ou, finalmente, por praias arenosas.

\section{SUMMARY}

The oceanographic work realized during 10 days in the surroundings of the eruptive island of Trindade, $20^{\circ} 30^{\prime} 36^{\prime \prime}$ lat. S $-29^{\circ} 19^{\prime} 26^{\prime \prime}$ long. W, had as principal aim the determination of the insular plateau, whose knowledge was very insufficient. Thus were established some oceanographic stations and sounding lines were realized by means of an echobathymeter whose responses were initially verified with mechanical soundings obtaneid by means of a Thomson sounder.

The insular plateau is very narrow and exhibits a sudden fall between the 100 and $120 \mathrm{~m}$. depth line at $740 \mathrm{~m}$. - $2950 \mathrm{~m}$. from the coast. Its greatest depth is of $108,30 \mathrm{~m}$. and its mean inclination is of $8,12 \%$. The plateau of the island of Trindade is separated from that of the neighbouring group of Martim Vaz by great depths. 
The bottoms are rocky near the coast, the blocks having been produced by the rupture of the magmatic mass of the island. Further away from the coast, the size of the rocks gradually diminishes up to the fine sand thickness. In the litoral zone there are abundant tufts of living Lithothamnion with a rich associated flora and fauna, which partly covers the rocks themselves. Further off at sea, the spheres of the dead alga with its commensals are cimented together by sedimentation. The spheres are further broken up and become an integrating part of the sand.

The results of the physical and chemical analyses of the sand bottoms are shown in tables 2 and 3 .

The coast is either of abrupt rocky walls falling down to sea level, or of shores, made of pebbles or of sand. Anyhow, there are frequently Lithothamnion terraces slightly inclinated towards the bottom (chemical analysis table 1). 


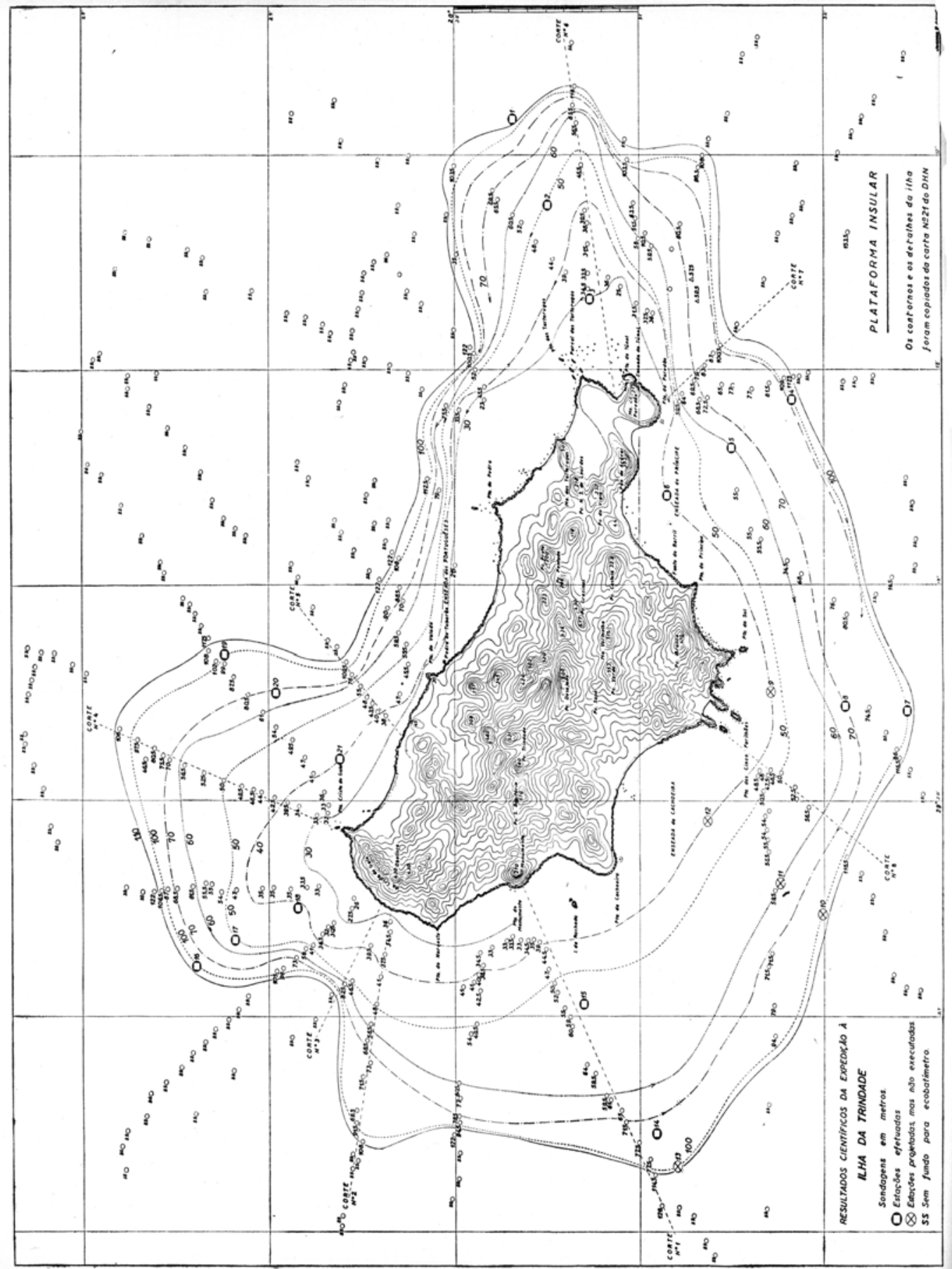


Besnard, W. Resultados cientificos do cruzeiro do "Baependi" e do "Vega"...
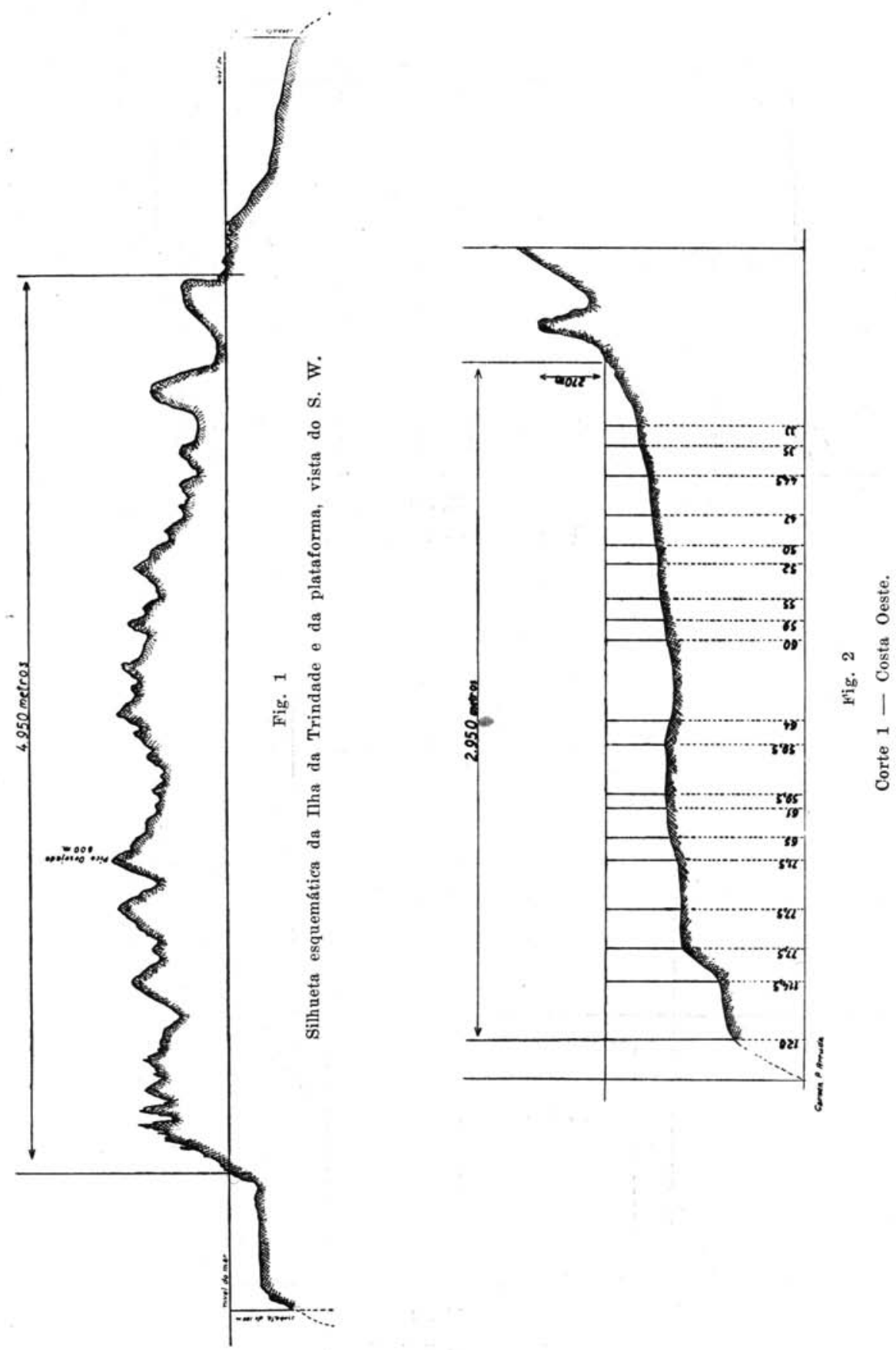
Besnard, W. Resultados cientificos do cruzeiro do "Baependi" e do "Vega"...

Estampa II

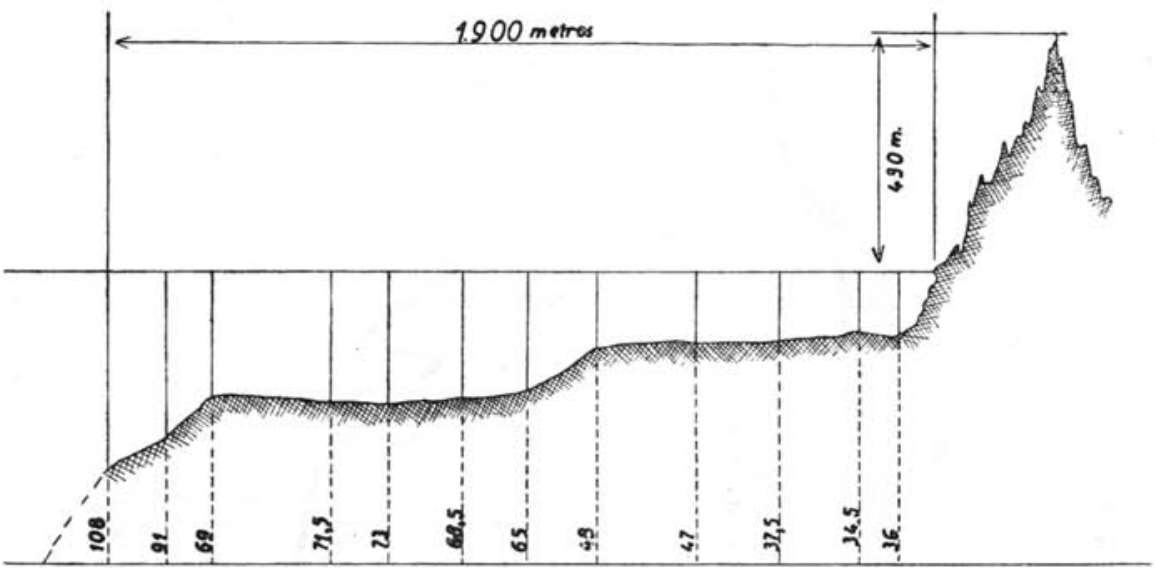

Fig. 3

Corte 2 - Costa Oeste.

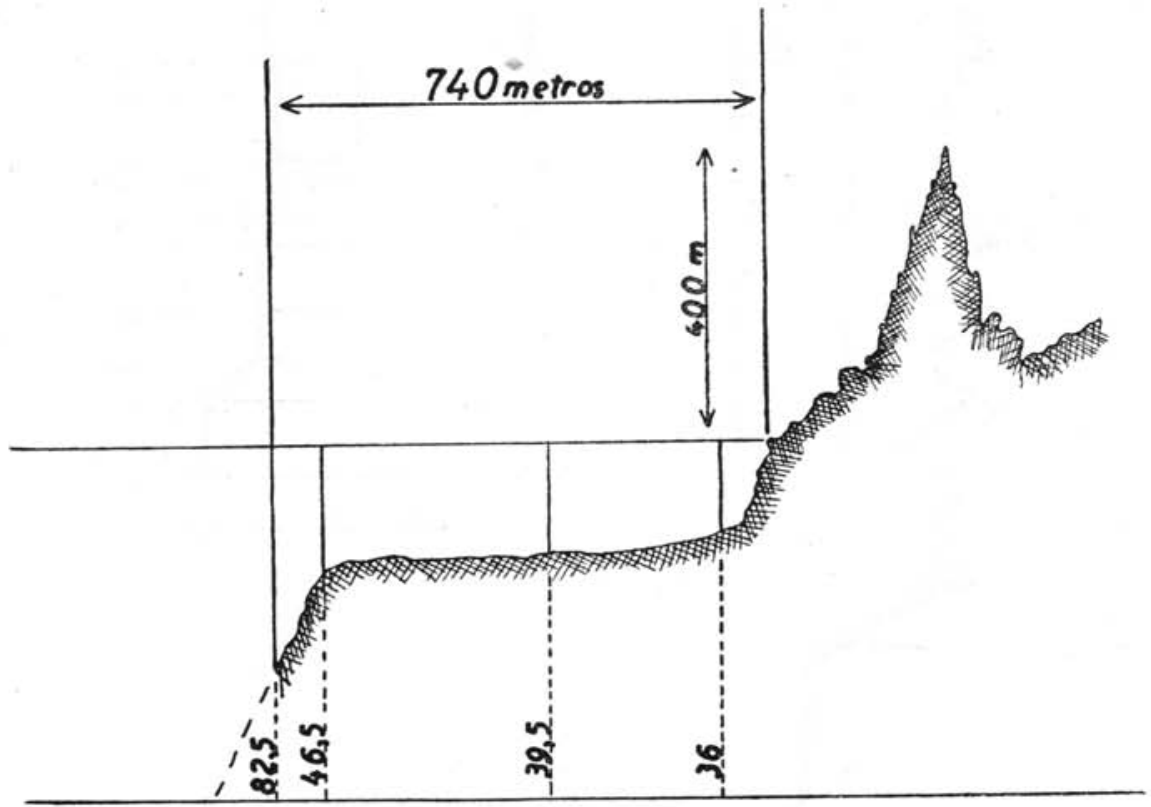

Fig. 4

Corte 3 - Costa Oeste. 
Besnard, W. Resultados científicos do eruzeiro do "Baependi" e do "Vega"...

Estampa III

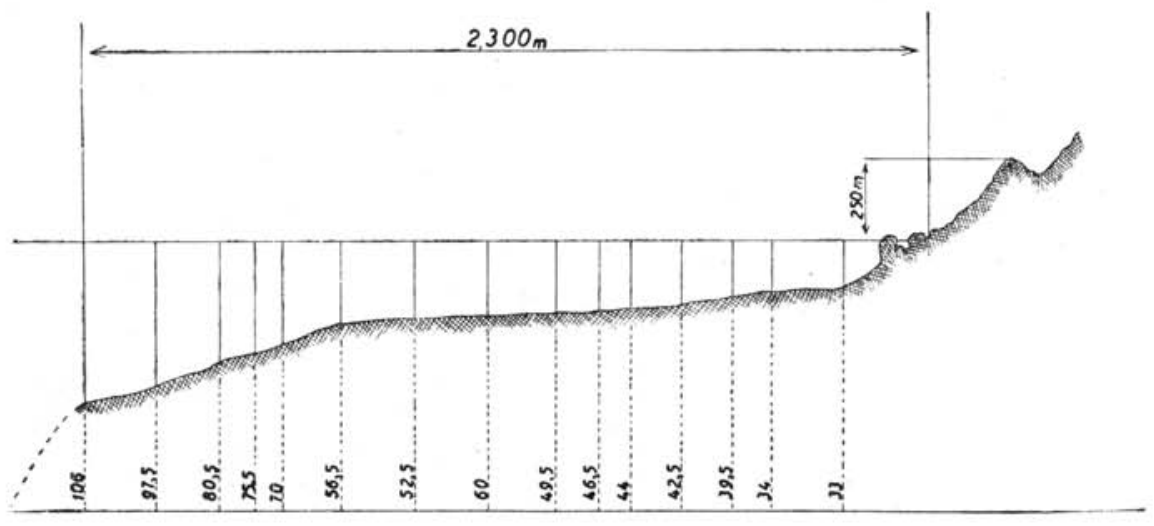

Fig. 5

Corte 4 - Costa Norte.

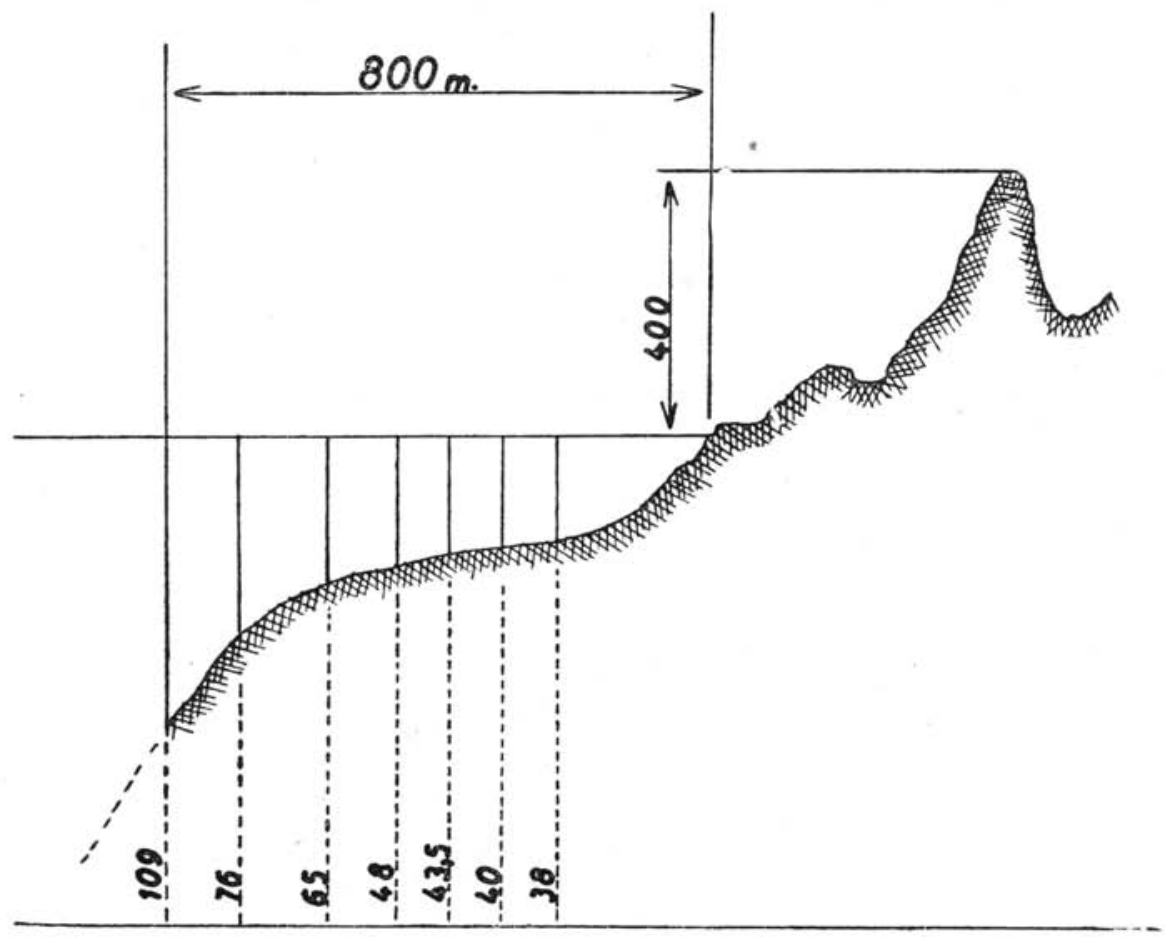

Fig. 6

Corte 5 - Costa Norte. 
Besnard, W. Resultados científicos do cruzeiro do "Baependi" e do "Vega"...

Estampa IV

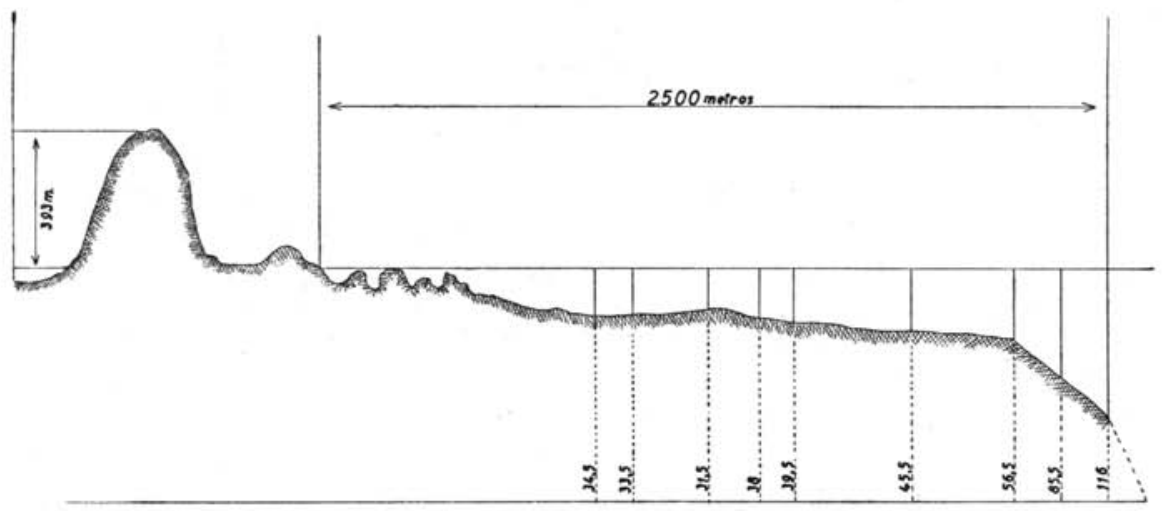

Fig. 7

Corte 6 - Costa Leste.

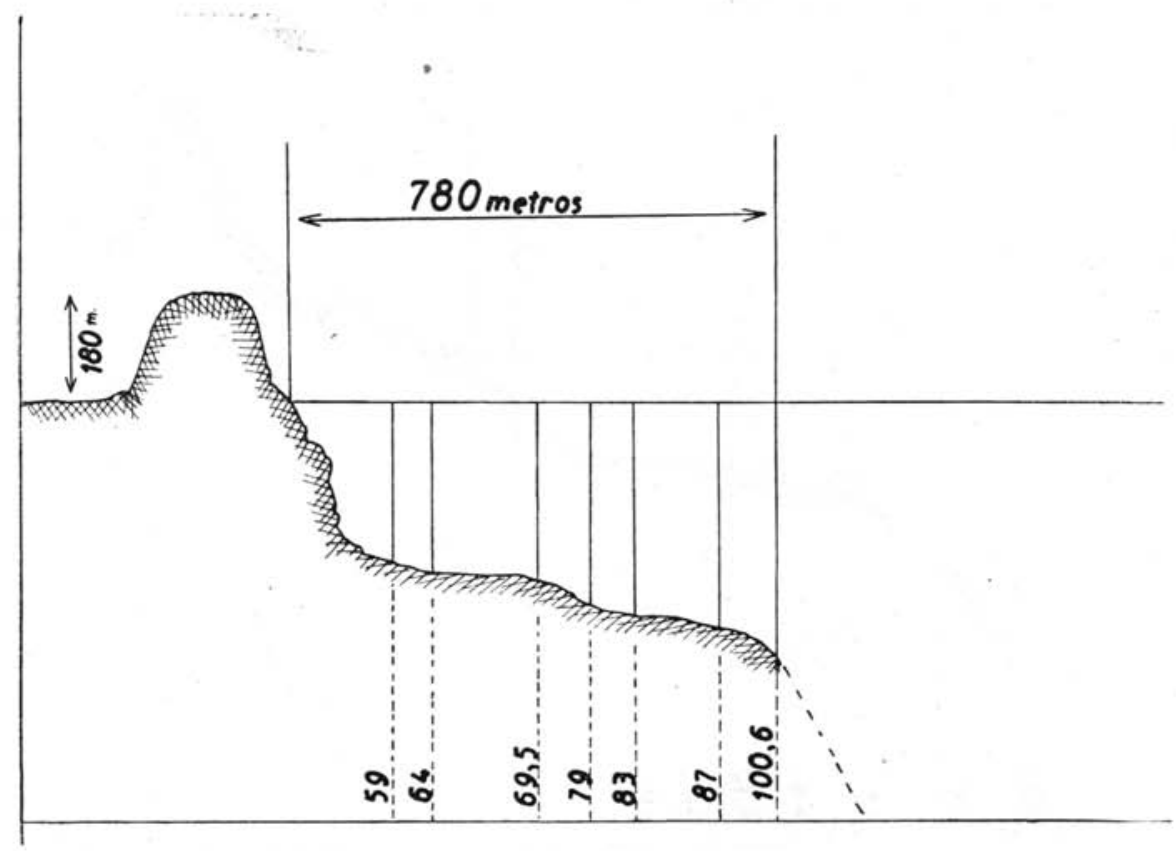

Fig. 8

Corte 7 - Costa Sul. 
Besnard, W., Resultados científicos do cruzeiro do "Baependi" e do "Vega"...

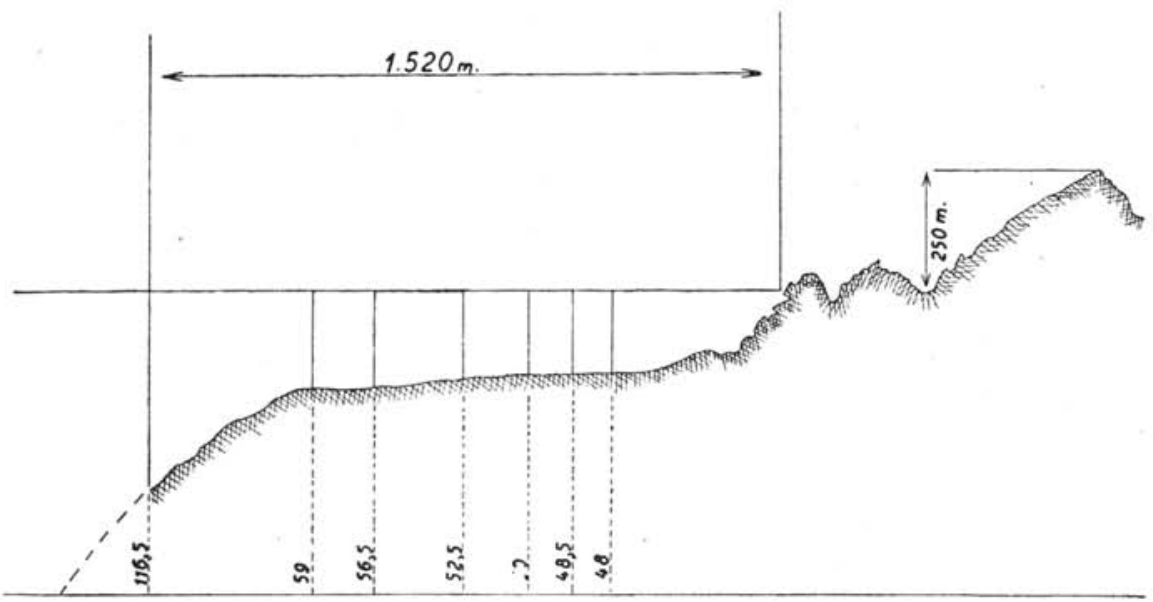

Fig. 9

Corte 8 - Costa Sul. 